\title{
An Efficient Approach to Quinolines via Friedländer Synthesis Catalyzed by Cuprous Triflate
}

\author{
Ebrahim Soleimani, ${ }^{*}$ Mohammad Mehdi Khodaei, ${ }^{*}$ Nasim Batooie, and Saadi Samadi \\ Department of Chemistry, Razi University; Kermanshah 67149, Iran.
}

Received September 15, 2009; accepted October 19, 2009; published online November 24, 2009

\begin{abstract}
A mild and efficient route for the synthesis of quinolines utilizing cuprous triflate $\left(\mathrm{Cu}(\mathrm{OTf})_{2}\right)$ as a novel catalyst via Friedländer annulation in excellent yields at room temperature under solvent-free conditions was described.
\end{abstract}

Key words Friedländer synthesis; quinoline; solvent-free; cuprous triflate

As a privileged fragment, quinoline is a ubiquitous subunit in many quinoline-containing natural products with remarkable biological activities. ${ }^{1-6)}$ Members of this family have wide applications in medicinal chemistry, being used as antimalarial, antiinflammatory agents, antiasthamatic, antibacterial, antihypertensive, and tyrosine kinase inhibiting agents. $^{1-6)}$ In addition, quinolines are valuable synthons used for the preparation of nano- and meso-structures with enhanced electronic and photonic properties. ${ }^{7-9)}$ Consequently, various procedures such as the Skraup, Doebner-Von Miller, Friedländer and Combes methods have been developed for the synthesis of quinoline derivatives. ${ }^{10-17)}$ Among them, the Friedländer annulation ${ }^{14)}$ is still one of the most simple and straightforward approaches for the synthesis of polysubstituted quinolines. The Friedländer quinoline synthesis consists of the reaction between a 2-aminoaryl ketones or aldehydes with $\alpha$-methylene ketones under acid catalysts. Brønsted acids like hydrochloric acid, sulfuric acid, $p$-toluene sulfonic acid and phosphoric acid were widely used as catalysts. ${ }^{18-21)}$ Recently, Lewis acids such as $\mathrm{ZnCl}_{2}, \mathrm{SnCl}_{2}$, silver phosphotungstate, sodium fluoride, Neodymium(III) Nitrate Hexahydrate, $\mathrm{CeCl}_{3} \cdot 7 \mathrm{H}_{2} \mathrm{O}$ and $\mathrm{AuCl}_{3}$ have been reported to be effective for the synthesis of quinolines. ${ }^{22-31)}$ However, many of these procedures suffered from harsh reaction conditions, low yields, difficulties in work up, and the use of stoichiometric and/or relatively expensive reagents.

In continuation of our efforts to develop new methods in the synthesis of quinolines, ${ }^{32-34)}$ herein, we wish to report a mild and efficient approach for the synthesis of polysubstituted quinolines via Friedländer annulation using a catalytic amount of cuprous triflate $\left(\mathrm{Cu}(\mathrm{OTf})_{2}\right)$ under solvent-free conditions at room temperature. Accordingly, treatment of 2aminoaryl ketones 1 with $\alpha$-methylene ketones 2 in the presence of $20 \mathrm{~mol} \%$ of $\mathrm{Cu}(\mathrm{OTf})_{2}$ resulted in the formation of quinolines 3 in high yields (Chart 1).

\section{Experimental}

A mixture of 2-aminoaryl ketone $(1 \mathrm{mmol}), \alpha$-methylene ketone $(1.2 \mathrm{mmol})$ and $\mathrm{Cu}(\mathrm{OTf})_{2}(0.2 \mathrm{mmol}, 20 \mathrm{~mol} \%)$ was stirred at room temperature for acyclic ketone and $60^{\circ} \mathrm{C}$ for cyclic ketone under solvent-free conditions for the appropriate time (Table 1). After completion of the reaction, as indicated by TLC, was added $10 \mathrm{ml}$ of water to the reaction mixture and the product was filtrated and washed with water $(2 \times 10 \mathrm{ml})$, and the solid product was recrystallized from ethanol to afford the pure product.

All the products are known compounds, which were characterized by IR and ${ }^{1} \mathrm{H}-\mathrm{NMR}$ spectral data and their mp's compared with literature reports. ${ }^{32-37)}$

\section{Results and Discussion}

To demonstrate the generality of this method, we next investigated the scope of this reaction and the results are sum-

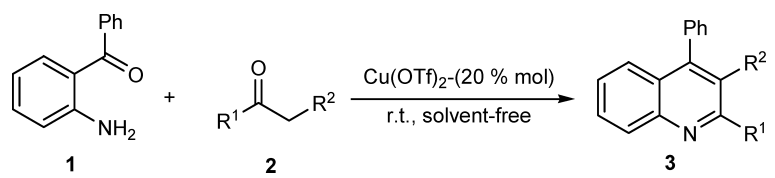

Chart 1. Synthesis of Quinolines

Table 1. Synthesis of the Quinolines in the Presence of Catalytic Amount of $\mathrm{Cu}(\mathrm{OTf})_{2}$ under Solvent Free Conditions

(n)


Table 2. Catalyst Effect on the Reaction

\begin{tabular}{lcc}
\hline \hline Catalyst & mol\% & Yield (\%) \\
\hline $\mathrm{ZnCl}_{2}$ & 50 & 50 \\
$\mathrm{SnCl}_{2}$ & 50 & 60 \\
$\mathrm{~K} 10$ & $0.1 \mathrm{~g}$ for $1 \mathrm{mmol}$ & 25 \\
$\mathrm{AcOH}$ & 50 & 20 \\
$\mathrm{PTSA}$ & 50 & 50 \\
$\mathrm{Cu}(\mathrm{OTf})_{2}$ & 50 & 99 \\
\hline
\end{tabular}

Table 3. Catalyst Amount on the Reaction

\begin{tabular}{ccc}
\hline \hline mol\% & Time $(\mathrm{h})$ & Yield (\%) \\
\hline 10 & 5 & 98 \\
20 & 2 & 99 \\
30 & 1.7 & 99 \\
50 & 1.5 & 98 \\
\hline
\end{tabular}

marized in Table 1. Various substituted 2-aminoaryl ketones such as 2-aminobenzophenone, and 2-amino-5-chloro-benzophenone reacted smoothly with $\alpha$-methylene ketones to produce a range of quinoline derivatives. The reaction was carried out at room temperature, when acyclic ketones were used as reagents, but when cyclic ketones were used as reagents the reaction was carried out at $60^{\circ} \mathrm{C}$. As shown in Table 1, this method is equally effective for both cyclic and acyclic ketones. In the absence of catalyst, the reaction did not yield any product even after long reaction time.

In order to optimize the reaction conditions, an experiment was conducted in which the reaction of 2-amino-5-chlorobenzophenone with methyl acetoacetate was studied with solvents and under solvent-free conditions. The results showed that the efficiency and the yield of the reaction under solvent-free condition were higher than those obtained in other solvents like EtOH, $\mathrm{H}_{2} \mathrm{O}$, toluene and $\mathrm{CH}_{3} \mathrm{CN}$. Also we examined this condensation reaction in the absence and the presence of several catalysts under solvent-free condition after $2 \mathrm{~h}$. The best results were obtained when $\mathrm{Cu}(\mathrm{OTf})_{2}$ was used (Table 2).

To optimize amount of $\mathrm{Cu}(\mathrm{OTf})_{2}$ for these reactions, the reaction of 2-amino-5-chloro-benzophenone with methyl acetoacetate was studied with $10,20,30$ and $50 \%$ mol of $\mathrm{Cu}(\mathrm{OTf})_{2}$ under solvent-free conditions. The desirable results were obtained when $20 \% \mathrm{~mol}$ of $\mathrm{Cu}(\mathrm{OTf})_{2}$ was used (Table 3 ).

\section{Conclusions}

In summary, we have described a mild and efficient protocol for the synthesis of quinolines and polycyclic quinolines via Friedländer condensation of 2-aminoaryl ketones with $\alpha$ methylene ketones using $\mathrm{Cu}(\mathrm{OTf})_{2}$ as catalyst. This method not only provides an excellent complement to quinolines synthesis via Friedländer annulation, but also avoids the use of hazardous acids or bases and harsh reaction conditions.

Acknowledgements We gratefully acknowledge financial support from the Research Council of Razi University.

\section{References}

1) Larsen R. D., Corley E. G., King A. O., Carrol J. D., Davis P., Verhoeven T. R., Reider P. J., Labelle M., Gauthier J. Y., Xiang Y. B., Zamboni R., J. Org. Chem., 61, 3398-3405 (1996).

2) Chen Y. L., Fang K. C., Sheu J. Y., Hsu S. L., Tzeng C. C., J. Med. Chem., 44, 2374-2377 (2001).

3) Roma G., Braccio M. D., Grossi G., Chia M., Eur. J. Med. Chem., 35, 1021 (2000).

4) Doube D., Bloun M., Brideau C., Chan C., Desmarais S., Eithier D., Falgueyeret J. P., Friesen R. W., Girad M., Girad Y., Guay J., Tagari P., Yong R. N., Bioorg. Med. Chem. Lett., 8, 1255-1260 (1998).

5) Maguire M. P., Sheets K. R., Mcvety K., Spada A. P., Zilberstein A., J. Med. Chem., 37, 2129-2137 (1994).

6) Bilker O., Lindo V., Panico M., Etiene A. E., Paxton T., Dell A., Rogers M., Sinden R. E., Morris H. R., Nature (London), 392, 289392 (1998).

7) Aggarwal A. K., Jenekhe S. A., Macromolecules, 24, 6806-6808 (1991).

8) Zhang X., Shetty A. S., Jenekhe S. A., Macromolecules, 32, 74227429 (1999).

9) Jenekhe S. A., Lu L., Alam M. M., Macromolecules, 34, 7315-7324 (2001).

10) Jones G., "Comprehensive Heterocyclic Chemistry II," Vol. 5, ed. by Katritzky A. R., Rees C. W., Scriven E. F. V., Pergamon, New York, 1996, p. 167.

11) Cho C. S., Oh B. H., Kim T. J., Shim S. C., Chem. Commun., 2000, 1885-1886 (2000).

12) Jiang B., Si Y. C., J. Org. Chem., 67, 9449—9451 (2002).

13) Skraup H., Chem. Ber., 13, 2086-2087 (1880).

14) Friedlander P., Chem. Ber, 15, 2572-2575 (1882).

15) Mansake R. H. F., Kulka M., Org. React., 7, 59-70 (1953)

16) Linderman R. J., Kirollos S. K., Tetrahedron Lett., 31, 2689-2692 (1990).

17) Theoclitou M. E., Robinson L. A., Tetrahedron Lett., 43, 3907-3910 (2002).

18) Fehnel E. A., J. Heterocycl. Chem., 4, 565-570 (1967).

19) Cheng C. C., Yan S. J., Org. React., 28, 37-45 (1982).

20) Sterkowski L., Czamy A., J. Fluorine Chem., 104, 281-284 (2000).

21) Hu Y.-Z., Zang G., Thummel R. P., Org. Lett., 5, $2251-2253$ (2003).

22) Arcadi A., Chiarini M., Di Giuseppe S., Marinelli F., Synlett, 2003, 203-206 (2003).

23) McNaughton B. R., Miller B. L., Org. Lett., 5, 4257-4259 (2003).

24) Yadav J. S., Reddy B. V., Premlatha K., Synlett, 2004, 963-966 (2004).

25) Yadav J. S., Reddy B. V., Sreedhar P., Rao R. S., Nagaiah K., Synthesis, 2004, 2381-2385 (2004).

26) Mogilaih K., Reddy C. S., Synth. Commun., 33, 3131-3134 (2003).

27) Walser A., Flyll T., Fryer R. I., J. Heterocycl. Chem., 12, 737-741 (1975).

28) De S, K., Gibbs R., Tetrahedron Lett., 46, 1647-1649 (2005).

29) Arumugam P., Karthikeyan G., Atchudan R., Muralidharan D., Perumal P. T., Chem. Lett., 34, 314-315 (2005).

30) Varala R., Enugala R., Adapa S. R., Synthesis, 2006, 3825-3831 (2006).

31) Bose D. S., Kumar R. K., Tetrahedron Lett., 47, 813-816 (2006).

32) Shaabani A., Soleimani E., Badri Z., Monatsh. Chem., 137, 181-184 (2006).

33) Shaabani A., Soleimani E., Badri Z., Synth. Commun., 37, 629-635 (2007).

34) Palimkar S. S., Siddiqui S. A., Daniel T., Lahoti R. J., Srinivasan K. V., J. Org. Chem., 68, 9371-9378 (2003).

35) Thummel R. P., Synlett, 1992, 1-12 (1992).

36) Eckert H., Angew. Chem., Int. Ed. Engl., 20, 208-210 (1981).

37) Gladiali S., Chelucci G., Mudadu M. S., Gastaut M. A., Thummel R. P., J. Org. Chem., 66, 400-405 (2001). 